The Astrophysical Journal, 522:L133-L136, 1999 September 10

(C) 1999. The American Astronomical Society. All rights reserved. Printed in U.S.A.

\title{
CIRCUMSTELLAR HIBONITE AND CORUNDUM AND NUCLEOSYNTHESIS IN ASYMPTOTIC GIANT BRANCH STARS
}

\author{
Byeon-Gak Choi, ${ }^{1}$ G. J. Wasserburg, ${ }^{1}$ And Gary R. Huss ${ }^{2}$ \\ Received 1999 June 25; accepted 1999 July 12; published 1999 August 12
}

\begin{abstract}
We report the discovery of two hibonite grains $\left(\mathrm{CaAl}_{12} \mathrm{O}_{19}\right)$ whose isotopic compositions show that they formed in the winds of red giant and asymptotic giant branch (AGB) stars. While hibonite is the second major phase (after corundum, $\mathrm{Al}_{2} \mathrm{O}_{3}$ ) expected to condense from stellar ejecta with $\mathrm{C} / \mathrm{O}<1$, it has not previously been found. One circumstellar hibonite grain is highly enriched in ${ }^{17} \mathrm{O}$ and slightly depleted in ${ }^{18} \mathrm{O}$ relative to the solar composition and has large excesses in ${ }^{26} \mathrm{Mg}$ and ${ }^{41} \mathrm{~K}$, decay products of ${ }^{26} \mathrm{Al}$ and ${ }^{41} \mathrm{Ca}$. The inferred initial values $\left({ }^{26} \mathrm{Al} /{ }^{27} \mathrm{Al}\right)_{0} \approx 5 \times 10^{-3}$ and $\left({ }^{41} \mathrm{Ca} /{ }^{40} \mathrm{Ca}\right)_{0} \approx 1.5 \times 10^{-4}$ of this grain are consistent with models of nucleosynthesis in an AGB star. The other hibonite is enriched in ${ }^{17} \mathrm{O}$, strongly depleted in ${ }^{18} \mathrm{O}$, shows no evidence of ${ }^{41} \mathrm{Ca}$ and formed with $\left({ }^{26} \mathrm{Al} /{ }^{27} \mathrm{Al}\right)_{0} \approx 2 \times 10^{-2}$. The low ${ }^{18} \mathrm{O} /{ }^{16} \mathrm{O}$ and very high $\left({ }^{26} \mathrm{Al} /{ }^{27} \mathrm{Al}\right)_{0}$ may indicate substantial proton exposure during cool bottom processing in a low-mass parent star. The low upper limit on ${ }^{41} \mathrm{Ca} /{ }^{40} \mathrm{Ca}(\leq 3.2 \times$ $10^{-5}$ ) implies that little or no He-shell material had been dredged into the envelope when this grain formed. We also report isotopic compositions for 12 new circumstellar corundum grains. The compositions of 11 of these grains are consistent with current models for red giant and AGB stars. One corundum grain has extremely high ${ }^{17} \mathrm{O} /{ }^{16} \mathrm{O}$ and near-solar ${ }^{18} \mathrm{O} /{ }^{16} \mathrm{O}$ and may have formed in a star that was initially enriched in ${ }^{17} \mathrm{O}$ and ${ }^{18} \mathrm{O}$.
\end{abstract}

Subject headings: nuclear reactions, nucleosynthesis, abundances — stars: AGB and post-AGB stars: winds, outflows

\section{INTRODUCTION}

Several types of presolar grains with highly anomalous isotopic signatures have been found in acid-residues of meteorites (see Zinner 1997). These grains are interpreted to have condensed from the winds or ejecta of red giant stars, asymptotic giant branch (AGB) stars, novae, supernovae, and Wolf-Rayet stars. The majority of known circumstellar condensates are Crich phases (e.g., Anders \& Zinner 1993; Zinner 1997). Oxide grains, which form in regimes where $\mathrm{C} / \mathrm{O}<1$, are much more difficult to find because of the overwhelming abundance of oxide grains of solar system origin in meteorites. Among the more than 120 oxide grains found prior to this study, corundum $\left(\mathrm{Al}_{2} \mathrm{O}_{3}\right)$ was the predominant phase and four spinel $\left(\mathrm{MgAl}_{2} \mathrm{O}_{4}\right)$ and one $\mathrm{TiO}_{2}$ have been found (Hutcheon et al. 1994; Huss et al. 1994; Nittler et al. 1994, 1997, 1998; Choi et al. 1998, hereafter CHWG; Nittler \& Alexander 1999). Circumstellar condensates provide information on stellar nucleosynthesis and demonstrate the chemical sequence of condensation, a near equilibrium process, and aspects of the gas-solid kinetics in circumstellar envelopes. Here we report the discovery of two circumstellar hibonite grains $\left(\mathrm{CaAl}_{12} \mathrm{O}_{19}\right)$, the second major phase after corundum to condense in equilibrium from stellar ejecta with $\mathrm{C} / \mathrm{O}<1$, and 12 additional circumstellar corundum grains, and present their isotopic compositions. Hibonite, with its high $\mathrm{Ca}$ and low $\mathrm{K}$ contents, provides an opportunity to study the production of the short-lived radioactive nuclide ${ }^{41} \mathrm{Ca}$, in addition to ${ }^{26} \mathrm{Al}$ and the $\mathrm{O}$ isotopes.

\section{EXPERIMENTAL PROCEDURES}

We used a scanning electron microscope with an automated scanning system (Heinrich, Huss, \& Wasserburg 1998; CHWG)

\footnotetext{
${ }^{1}$ The Lunatic Asylum, 170-25, Division of Geological and Planetary Sciences, California Institute of Technology, Pasadena, CA 91125; bchoi@ gps.caltech.edu, isotopes@gps.caltech.edu.

${ }^{2}$ Department of Geology, Arizona State University, Tempe, AZ 85287-1404; gary.huss@asu.edu.
}

to locate and determine the chemical compositions of the refractory grains in an acid-residue of the Semarkona ordinary chondrite. We selected single-crystal, Al-rich, oxide grains and subjected them to isotopic analyses using PANURGE, a modified Cameca ims $3 \mathrm{f}$ ion microprobe. Analytical procedures for $\mathrm{O}, \mathrm{Al}$, and $\mathrm{Mg}$ were similar to those described in Hutcheon et al. (1994) and Huss, Hutcheon, \& Wasserburg (1997). Calcium$\mathrm{K}$ systematics were measured with a mass resolving power of $\sim 4700$, which separates all hydrides. The ${ }^{40} \mathrm{Ca}^{42} \mathrm{Ca}^{++}$cannot be separated from ${ }^{41} \mathrm{~K}^{+}$under these conditions. Following the method of Hutcheon, Armstrong, \& Wasserburg (1984), we monitored mass 41.5 to measure ${ }^{40} \mathrm{Ca}^{43} \mathrm{Ca}^{++}$and estimated the ${ }^{40} \mathrm{Ca}^{42} \mathrm{Ca}^{++}$interference on ${ }^{41} \mathrm{~K}^{+}$by assuming that ${ }^{40} \mathrm{Ca}^{42} \mathrm{Ca}^{++} /{ }^{42} \mathrm{Ca}^{+}={ }^{40} \mathrm{Ca}^{43} \mathrm{Ca}^{++} /{ }^{43} \mathrm{Ca}^{+}$. The estimated ratios of ${ }^{40} \mathrm{Ca}^{42} \mathrm{Ca}^{++} /{ }^{41} \mathrm{~K}^{+}$were less than $10^{-3}$. The interferences of ${ }^{84} \mathrm{Sr}^{++},{ }^{86} \mathrm{Sr}^{++}$, and ${ }^{88} \mathrm{Sr}^{++}$in ${ }^{42} \mathrm{Ca}^{+},{ }^{43} \mathrm{Ca}^{+}$, and ${ }^{44} \mathrm{Ca}^{+}$are unimportant because the two circumstellar hibonite grains have ${ }^{88} \mathrm{Sr}^{+} /{ }^{40} \mathrm{Ca}^{+}<10^{-6}$.

\section{RESULTS}

We measured $\mathrm{O}$ isotopic compositions of 57 hibonite and 149 corundum grains. Two hibonite and 12 corundum grains were found to have ${ }^{18} \mathrm{O} /{ }^{16} \mathrm{O}$ and ${ }^{17} \mathrm{O} /{ }^{16} \mathrm{O}$ indicative of circumstellar origins (Table 1). All other grains have $\mathrm{O}$ compositions that fall in the narrow range occupied by materials processed in the solar system. The identification of hibonite is based on the $\mathrm{Ca} / \mathrm{Al}$ ratio in $\mathrm{X}$-ray spectra and ion probe measurements. The two hibonite grains (S-H5323, Fig. 1, and S-H6205) have O compositions within the range of previously identified circumstellar oxide grains (Fig. 2). Hibonite S-H5323 is enriched in ${ }^{17} \mathrm{O}\left({ }^{17} \mathrm{O} /{ }^{16} \mathrm{O}=3.3 \times\right.$ solar $)$ and slightly depleted in ${ }^{18} \mathrm{O}$ $\left({ }^{18} \mathrm{O} /{ }^{16} \mathrm{O}=0.76 \times\right.$ solar). Hibonite $\mathrm{S}-\mathrm{H} 6205$ is also enriched in ${ }^{17} \mathrm{O}\left({ }^{17} \mathrm{O} /{ }^{16} \mathrm{O}=3.4 \times\right.$ solar $)$ and greatly depleted in ${ }^{18} \mathrm{O}$ $\left({ }^{18} \mathrm{O} /{ }^{16} \mathrm{O}=0.03 \times\right.$ solar $)$. Eleven of the 12 anomalous corundum grains in this study have $\mathrm{O}$ compositions that fall in the range occupied by previously studied circumstellar oxides 
TABLE 1

Oxygen and Al-Mg Isotopic Compositions of Corundum and Hibonite Grains

\begin{tabular}{|c|c|c|c|c|c|c|}
\hline Sample & ${ }^{17} \mathrm{O} /{ }^{16} \mathrm{O}$ & ${ }^{18} \mathrm{O} /{ }^{16} \mathrm{O}$ & ${ }^{25} \mathrm{Mg} /{ }^{24} \mathrm{Mg}$ & ${ }^{26} \mathrm{Mg} /{ }^{24} \mathrm{Mg}$ & ${ }^{27} \mathrm{Al} /{ }^{24} \mathrm{Mg}$ & $\left({ }^{26} \mathrm{Al} /{ }^{27} \mathrm{Al}\right)_{0}$ \\
\hline Solar & $3.828 \times 10^{-4}$ & $2.0052 \times 10^{-3}$ & 0.12663 & 0.13932 & & \\
\hline S-H5323 & $1.26(3) \times 10^{-3}$ & $1.52(6) \times 10^{-3}$ & $.1211(38)$ & $0.5482(113)$ & $86.2(87)$ & $4.7(5) \times 10^{-3}$ \\
\hline S-H6205 & $1.27(3) \times 10^{-3}$ & $6.2(1.5) \times 10^{-5}$ & $0.1303(24)$ & $0.8648(100)$ & $37.0(37)$ & $2.0(2) \times 10^{-2}$ \\
\hline S-C5132 & $2.8(4) \times 10^{-4}$ & $9.3(12) \times 10^{-4}$ & $0.1266(18)$ & $0.1412(19)$ & $56.1(56)$ & $<6.7 \times 10^{-5}$ \\
\hline S-C5158 & $6.4(7) \times 10^{-4}$ & $1.36(19) \times 10^{-3}$ & & & & \\
\hline S-C5167 & $8.2(5) \times 10^{-4}$ & $1.30(12) \times 10^{-3}$ & 0.117 & $0.1589(201)$ & $2706(333)$ & $<1.5 \times 10^{-5}$ \\
\hline S-C5186 & $4.6(13) \times 10^{-}$ & $1.14(34) \times 10^{-3}$ & 0.12 & 0.1 & 9.3 & $<6.4 \times 10$ \\
\hline S-C5218 & $3.5(7) \times 10^{-4}$ & $2.31(31) \times 10^{-3}$ & $0.1314(62)$ & $0.1585(70)$ & $32.0(33)$ & $0(23)$ \\
\hline S-C5223 & $5.3(12) \times 10^{-4}$ & $1.92(40) \times 10^{-3}$ & . & $\ldots$ & . & \\
\hline S-C5227 & $2.51(17) \times 10^{-3}$ & $1.21(22) \times 10^{-3}$ & $0.1312(7$ & $0.4529(188)$ & $183(19)$ & $1.7(2) \times 10^{-3}$ \\
\hline S-C6013 & $3.0(3) \times 10^{-4}$ & $1.67(14) \times 10^{-3}$ & 0.12 & & 51. & $<9.9 \times 10$ \\
\hline- -C6071 & $1.22(4) \times 10^{-3}$ & $1.5(3) \times 10^{-4}$ & 0.12 & 0.33 & $17.3(17)$ & $1.1(1) \times 10$ \\
\hline$-\mathrm{C} 6087$ & $7.52(5) \times 10^{-3}$ & $2.18(5) \times 10^{-3}$ & 0.131 & 0.144 & $402(41)$ & $<2.7 \times 10^{-5}$ \\
\hline S-C6106 & $1.03(3) \times 10^{-3}$ & $2.9(3) \times 10^{-4}$ & 0.1250 & $3.6237(961)$ & $112(12)$ & $3.1(3) \times 10^{-2}$ \\
\hline S-C6121 & $7.1(4) \times 10^{-4}$ & $1.15(8) \times 10^{-3}$ & $0.1265(28)$ & $0.1395(30)$ & 20.1(20) & $<1.5 \times 10^{-4}$ \\
\hline
\end{tabular}

Notes. -Errors $(2 \sigma)$ are given in parentheses, for example, $1.26(3) \times 10^{-3}=(1.26 \pm 0.03) \times 10^{-3}$. In sample names, the first letter indicates the source meteorite (Semarkona) and the second letter designates either corundum (C) or hibonite $(\mathrm{H})$. Ellipses (...) indicate not applicable or not measured. In the text, some ratios are reported using the delta notation, for example, $\left.\delta^{25} \mathrm{Mg}(\% o)=\left[{ }^{25} \mathrm{Mg} /{ }^{24} \mathrm{Mg}\right) /\left({ }^{25} \mathrm{Mg} /{ }^{24} \mathrm{Mg}\right)-1\right] \times 1000$, where the subscript $m$ is for measured ratio and $s$ for the solar ratio.

(Fig. 2). Corundum S-C6087 is extremely enriched in ${ }^{17} \mathrm{O}$ $\left({ }^{17} \mathrm{O} /{ }^{16} \mathrm{O}=20 \times\right.$ solar $)$, but it has near-solar ${ }^{18} \mathrm{O} /{ }^{16} \mathrm{O}$.

The ${ }^{25} \mathrm{Mg} /{ }^{4} \mathrm{Mg}$ ratios of 10 of the circumstellar corundum grains are normal within errors (the other two grains were not measured). Four grains have large excesses in ${ }^{26} \mathrm{Mg}$, which are inferred to be due to in situ decay of ${ }^{26} \mathrm{Al}$ (Table 1). The inferred initial ${ }^{26} \mathrm{Al} /{ }^{27} \mathrm{Al}$ ratios $\left[\left({ }^{26} \mathrm{Al} /{ }^{27} \mathrm{Al}\right)_{0}\right]$ range up to $\sim 3 \times 10^{-2}$. Hibonite S-H5323 shows a hint of depletion in ${ }^{25} \mathrm{Mg}\left(\delta^{25} \mathrm{Mg}=\right.$ $-44 \pm 30 \%$, see Table 1) and a large excess in ${ }^{26} \mathrm{Mg}$ $\left({ }^{26} \mathrm{Mg} /{ }^{24} \mathrm{Mg}=4 \times\right.$ solar $)$, which gives $\left({ }^{26} \mathrm{Al} /{ }^{27} \mathrm{Al}\right)_{0}=(4.7 \pm$ $0.5) \times 10^{-3}$. Hibonite S-H6025 may be slightly enriched in ${ }^{25} \mathrm{Mg}\left(\delta^{25} \mathrm{Mg}=29 \pm 19 \%\right.$ o $)$ and has ${ }^{26} \mathrm{Mg} /{ }^{24} \mathrm{Mg}=6 \times$ solar, which gives $\left({ }^{26} \mathrm{Al} /{ }^{27} \mathrm{Al}\right)_{0}$ of $(2.0 \pm 0.2) \times 10^{-2}$.

Calcium and $\mathrm{K}$ data for the two hibonite grains are summarized in Table 2. Hibonite S-H5323 has a small excess in ${ }^{42} \mathrm{Ca}\left(\delta^{42} \mathrm{Ca}=66 \pm 42 \%\right.$ ) but the ${ }^{43,44} \mathrm{Ca} /{ }^{40} \mathrm{Ca}$ ratios cannot be resolved from the solar composition. The $\mathrm{Ca}$ isotopic composition of S-H6205 is solar within uncertainties. Hibonite SH5323 has a large excess in ${ }^{41} \mathrm{~K}\left({ }^{41} \mathrm{~K} /{ }^{39} \mathrm{~K}=5 \times\right.$ solar $)$. Since

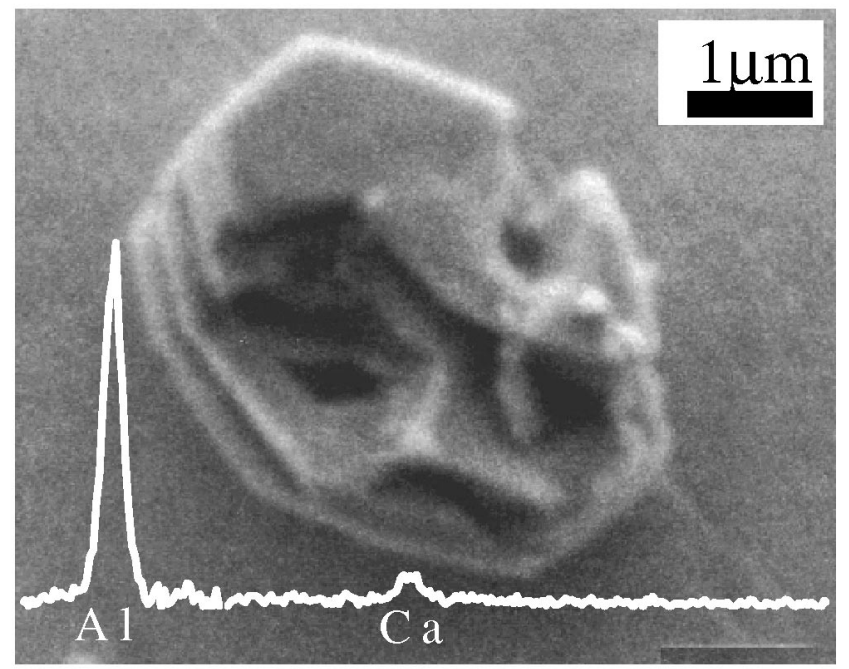

FIG. 1.-Secondary electron image of circumstellar hibonite S-H5323. The $\mathrm{X}$-ray spectrum is shown by the white line. Note the platy structure and the crystal faces on each plate.
${ }^{41} \mathrm{~K} /{ }^{39} \mathrm{~K}$ in the envelope of an AGB star should be only increased a few percent (Gallino et al. 1990), the large excess in ${ }^{41} \mathrm{~K}$ of S-H5323 is inferred to be the result of ${ }^{41} \mathrm{Ca}$ decay. The ${ }^{40} \mathrm{Ca} /$ ${ }^{39} \mathrm{~K}$ of $1.9 \times 10^{3}$ in $\mathrm{S}-\mathrm{H} 5323$ gives $\left({ }^{41} \mathrm{Ca} /{ }^{40} \mathrm{Ca}\right)_{0}=(1.5 \pm$ $0.2) \times 10^{-4}$. Hibonite S-H6205, which has a higher $\left({ }^{26} \mathrm{Al} /{ }^{27} \mathrm{Al}\right)_{0}$ than S-H5323, does not have a measurable excess in ${ }^{41} \mathrm{~K}$ $\left(\delta^{41} \mathrm{~K}=139 \pm 260 \%\right.$ o $)$. The ${ }^{40} \mathrm{Ca} /{ }^{\beta 9} \mathrm{~K}$ of 930 gives an upper

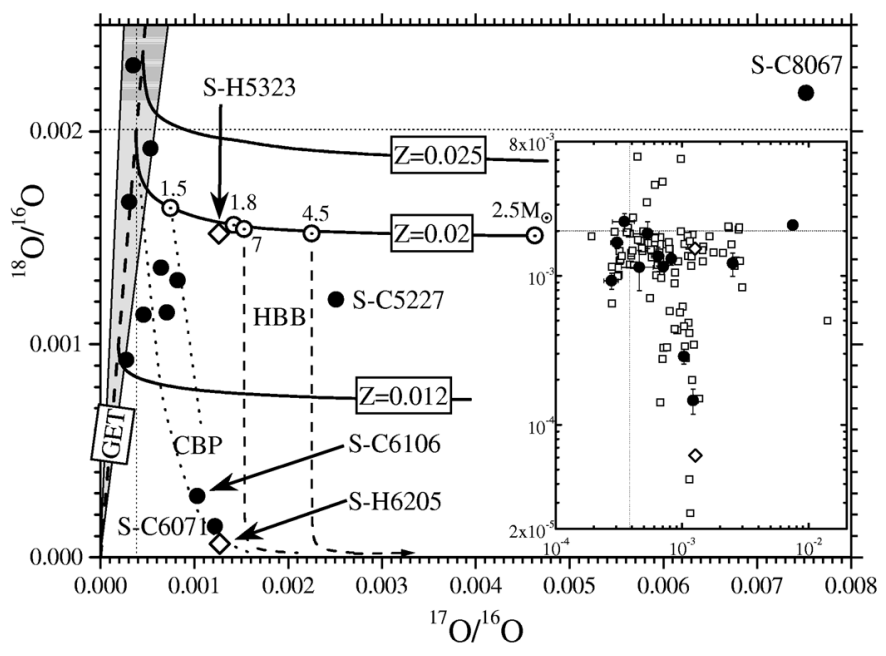

FIG. 2.-Oxygen composition of circumstellar hibonite (diamonds) and corundum (filled circles) from this study are shown along with model calculations (Boothroyd et al. 1994; Boothroyd \& Sackmann 1999). The initial compositions are assumed to be a function of metallicity $(Z)$ and to fall along the galactic evolution trend (GET; heavy-dashed line). A band along the GET represents a possible variation in the initial compositions (CHWG). Each solid line represents an array of envelope compositions for stars of various initial masses and a single metallicity. The dot-centered circles along $Z=0.02$ (solar) are for initial masses, 1.5, 1.8, 7, 4.5 and $2.5 M_{\odot}$. Dashed lines show the effects of HBB, in AGB stars of 4.5-7 $M_{\odot}$. The effects of CBP in 1 and 1.5 $M_{\odot}$ stars are shown by dotted lines. Note that the two hibonite grains and all but one of the corundum grains from this study can be understood in terms of the above processes. However, S-C6087 falls far outside of the region that can be understood with current theory. Vertical and horizontal lines show solar ratios. The inset shows compositions of oxide grains from this study and those previously identified (squares) (Hutcheon et al. 1994; Huss et al. 1994; Nittler et al. 1994, 1997; CHWG). Error bars for previously identified grains are not shown. 
TABLE 2

Calcium-K Isotopic Compositions of Hibonite Grains

\begin{tabular}{llllllr}
\hline \hline \multicolumn{1}{c}{ Sample } & \multicolumn{1}{c|}{${ }^{41} \mathrm{~K} /{ }^{39} \mathrm{~K}$} & \multicolumn{1}{c}{${ }^{42} \mathrm{Ca} /{ }^{40} \mathrm{Ca}$} & \multicolumn{1}{c}{${ }^{43} \mathrm{Ca} /{ }^{40} \mathrm{Ca}$} & \multicolumn{1}{c}{${ }^{44} \mathrm{Ca} /{ }^{40} \mathrm{Ca}$} & ${ }^{40} \mathrm{Ca} /{ }^{39} \mathrm{~K}$ & \multicolumn{1}{c}{$\left({ }^{41} \mathrm{Ca} /{ }^{40} \mathrm{Ca}\right)_{0}$} \\
\hline Solar ......... & 0.072 & 0.006621 & 0.001376 & 0.021208 & $\ldots$ & $\ldots$ \\
S-H5323 ...... & $0.352(26)$ & $0.00706(27)$ & $0.00146(10)$ & $0.02090(48)$ & $1917(209)$ & $1.5(2) \times 10^{-4}$ \\
S-H6205 ...... & $0.082(19)$ & $0.00652(51)$ & $0.00125(17)$ & $0.02179(95)$ & $927(108)$ & $<3.2 \times 10^{-5}$ \\
\hline
\end{tabular}

Notes. - Reported ${ }^{40} \mathrm{Ca} /{ }^{39} \mathrm{~K}$ were corrected for relative ion yield $(\mathrm{Ca} / \mathrm{K})$ of $3.3 \pm 0.3$. We cannot rule out the possibility that some of measured $\mathrm{K}$ was from small $\mathrm{K}$-bearing terrestrial contaminants near the hibonite grains. However, such a contribution does not affect the final $\left({ }^{41} \mathrm{Ca} /{ }^{40} \mathrm{Ca}\right)_{0}$-values. See also note for Table 1 .

limit of $\left({ }^{41} \mathrm{Ca} /{ }^{40} \mathrm{Ca}\right)_{0} \leq 3.2 \times 10^{-5}$. Corundum grains have very low $\mathrm{Ca}$ contents $\left(\mathrm{Ca} / \mathrm{Al}<10^{-3}\right)$ and were not measured for $\mathrm{Ca}$ and $\mathrm{K}$.

\section{DISCUSSIONS}

\subsection{The Morphology and Significance of Circumstellar Hibonite}

The two hibonite grains exhibit clear crystal faces. Figure 1 shows that S-H5323 consists of several "plates" with the same orientation. Hibonite S-H6205 consists of a single subhedral "plate." At equilibrium, the first major phase to condense in a gas with $\mathrm{C} / \mathrm{O}<1$ is corundum, followed by hibonite, perovskite $\left(\mathrm{CaTiO}_{3}\right)$, melilite $\left(\mathrm{Ca}_{2}\left[\mathrm{Al}, \mathrm{Mg}, \mathrm{Si}_{3} \mathrm{O}_{7}\right)\right.$, and spinel (e.g., Wood \& Hashimoto 1993; Yoneda \& Grossman 1995). However, perovskite and melilite do not survive the chemical procedures used to separate presolar grains (see Huss \& Lewis 1995), so their absence among known circumstellar grains is no surprise. Hibonite is not destroyed by the chemical procedures and is stable over a larger temperature range than is corundum (Wood \& Hashimoto 1993; Yoneda \& Grossman 1995). Thus, it is puzzling that no circumstellar hibonite was found prior to this study. This may reflect in part the larger background of solar system hibonite compared to corundum in meteorites. The discovery of circumstellar hibonite suggests that circumstellar perovskite and melilite may also exist in meteorites.

\subsection{Nucleosynthesis of O Isotopes in Low- and Intermediate-mass Stars}

Nucleosynthesis of $\mathrm{O}$ isotopes has been subjected to extensive theoretical investigations (Dearborn 1992; Boothroyd, Sackmann, \& Wasserburg 1994; Boothroyd \& Sackmann 1999). In low- and intermediate-mass stars, partial H burning via the $\mathrm{CN}$ and $\mathrm{CNO}$ cycles occurs at the base of the radiative envelope during the main sequence. The products of this burning are mixed into the envelope when the star becomes a red giant (known as the first dredge-up). In stars larger than $\sim 3.5$ $M_{\odot}$, additional products of stellar burning are brought to the surface by the second dredge-up that occurs at the end of core $\mathrm{He}$ burning. In the envelope, ${ }^{18} \mathrm{O}$ drops slightly and ${ }^{17} \mathrm{O}$ increases greatly after these dredge-ups (Fig. 2). The many mixing events of the third dredge-up, which occur during the thermally pulsing AGB phase, do little to modify the envelope O composition. Two additional processes are known to modify the envelope $\mathrm{O}$ compositions. In stars of $\sim 4.5$ to $\sim 7 M_{\odot}$, temperatures in the bottom of convective envelopes are high enough for nuclear processing, known as hot bottom burning (HBB) to occur during the AGB phase (e.g., Boothroyd, Sackmann, \& Wasserburg 1995). HBB reduces ${ }^{18} \mathrm{O} /{ }^{16} \mathrm{O}$ and then increases ${ }^{17} \mathrm{O} /{ }^{16} \mathrm{O}$ in the envelope (Fig. 2). In stars of less than $\sim 2.5 M_{\odot}$, cool bottom processing (CBP) may occur during the red giant and AGB phases. CBP slowly mixes envelope ma- terial down to the outer wing of the $\mathrm{H}$ shell (Wasserburg, Boothroyd, \& Sackmann 1995), lowering ${ }^{18} \mathrm{O} /{ }^{16} \mathrm{O}$ and increasing ${ }^{17} \mathrm{O} /{ }^{16} \mathrm{O}$ (Fig. 2).

The above processes can account for the compositions of a majority of oxide grains found to date, provided that there was some variation in initial compositions of source stars across the Galactic evolution trend (CHWG). Among the grains reported here, 10 corundum grains have compositions consistent with origins in low-mass stars $\left(\leq 1.5 M_{\odot}\right)$ with a range of metallicities (Fig. 2). Corundum S-C5227 apparently came from a more-massive (either $\sim 2 M_{\odot}$ or $\sim 4 M_{\odot}$ ) star (Fig. 2). Hibonite S-H5323 has a composition consistent with a star of $\sim 1.7 M_{\odot}$ and metallicity near solar. Grains S-H6205, S-C6071, and S-C6106 may have come from lower-mass stars that had experienced considerable CBP. Corundum S-C6087 has an unusually large excess of ${ }^{17} \mathrm{O}$ and a near solar ${ }^{18} \mathrm{O} /{ }^{16} \mathrm{O}$ ratio. This grain falls in a region that does not appear to be accessible via any of the processes discussed above (Fig. 2). Both CBP and HBB can increase ${ }^{17} \mathrm{O} /{ }^{16} \mathrm{O}$ in the envelope, but greatly decrease ${ }^{18} \mathrm{O} /{ }^{16} \mathrm{O}$. Thus, neither HBB nor $\mathrm{CBP}$ can explain grain $\mathrm{S}$ C6087. One possibility is that the parent star for S-C6087 was more highly enriched in both ${ }^{17} \mathrm{O}$ and ${ }^{18} \mathrm{O}$ than stars of the Galactic evolution trend. Additional theoretical work will be required to understand the origin of S-C6087.

\subsection{Short-lived Radioactive Nuclides, ${ }^{26} \mathrm{Al}$ and ${ }^{41} \mathrm{Ca}$}

In the $\mathrm{H}$ shell, ${ }^{26} \mathrm{Al}$ (mean life $=1.06 \mathrm{Myr}$ ) is produced via ${ }^{25} \operatorname{Mg}(p, \gamma){ }^{26} \mathrm{Al}$ (Forestini, Paulus, \& Arnould 1991; Gallino et al. 1994). In the He shell, ${ }^{26} \mathrm{Al}$ is destroyed by ${ }^{26} \mathrm{Al}(n, p)^{26} \mathrm{Mg}$ and by ${ }^{26} \mathrm{Al}(n, \alpha)^{23} \mathrm{Na}$ reactions. The calculated ${ }^{26} \mathrm{Al} /{ }^{27} \mathrm{Al}$ ratios are $\sim 0.6$ in the $\mathrm{H}$ shell and $\sim 0.08$ in the He shell of $\sim 1.5 M_{\odot}$ AGB star, although the final ratios remain uncertain due to inadequate knowledge of some reaction rates (Wasserburg et al. 1994; Busso, Gallino, \& Wasserburg 1999). The nuclide ${ }^{41} \mathrm{Ca}$ (mean life $=0.14 \mathrm{Myr}$ ) is produced via ${ }^{40} \mathrm{Ca}(n, \gamma){ }^{41} \mathrm{Ca}$ in the He shell. The expected ${ }^{41} \mathrm{Ca} /{ }^{40} \mathrm{Ca}$ in the $\mathrm{He}$ shell is $\sim 1.2 \times 10^{-2}$ (Cameron 1993). The $\mathrm{He}$ and $\mathrm{H}$ shell contribute up to $\sim 1 \%$ each to the envelope of an AGB star after many third dredge-up mixing events (Wasserburg et al. 1994; Busso et al. 1999). Thus, ${ }^{41} \mathrm{Ca} /{ }^{40} \mathrm{Ca} \approx 1.2 \times 10^{-4}$ and ${ }^{26} \mathrm{Al} /{ }^{27} \mathrm{Al} \approx$ $6 \times 10^{-3}$ are expected in the envelope of $\sim 1.5 M_{\odot}$ AGB star. The calculated values agree well with the measured values $\left(\sim 1.5 \times 10^{-4}\right.$ and $\sim 4.7 \times 10^{-3}$, respectively) in S-H5323, which has oxygen indicative of origin in $\sim 1.7 M_{\odot}$ AGB star. In the $\mathrm{He}$ shell, ${ }^{42} \mathrm{Ca} /{ }^{40} \mathrm{Ca},{ }^{43} \mathrm{Ca} /{ }^{40} \mathrm{Ca},{ }^{44} \mathrm{Ca} /{ }^{40} \mathrm{Ca},{ }^{46} \mathrm{Ca} /{ }^{40} \mathrm{Ca}$, and ${ }^{48} \mathrm{Ca} /{ }^{40} \mathrm{Ca}$ are expected to be $5.5,7.5,2.6,20$, and 1.5 times the initial ratios, respectively (Gallino et al. 1990). After mixing with the envelope, excesses of $\sim 6 \%, 8 \%, 3 \%, 20 \%$, and $2 \%$, respectively, would be observed with the typical dilution factor of 0.01 . The measured ${ }^{42} \mathrm{Ca}$ excess in S-H5323 is consistent with this, but the effects in ${ }^{43} \mathrm{Ca} /{ }^{40} \mathrm{Ca}$ and ${ }^{44} \mathrm{Ca} /{ }^{40} \mathrm{Ca}$ cannot be resolved with our data. Calcium- 46 and ${ }^{48} \mathrm{Ca}$ could not be measured because of isobaric interferences from ${ }^{46} \mathrm{Ti}$ and ${ }^{48} \mathrm{Ti}$. Other 
elements with $s$-process signatures (e.g., Ba, Sm, Dy) could not be measured because of low ion signals.

In contrast, hibonite $\mathrm{S}-\mathrm{H} 6205$, which has a higher $\left({ }^{26} \mathrm{Al} /{ }^{27} \mathrm{Al}\right)_{0}$ than S-H5323, has an upper limit of $\left({ }^{41} \mathrm{Ca} /{ }^{40} \mathrm{Ca}\right)_{0} \leq 3.2 \times$ $10^{-5}$, a factor of 50 below that observed for S-H5323. These observations are not in accord with the theoretical calculations described above. Oxide grains with low ${ }^{18} \mathrm{O} /{ }^{16} \mathrm{O}$, suggestive of CBP tend to have higher $\left({ }^{26} \mathrm{Al} /{ }^{27} \mathrm{Al}\right)_{0}$ ratios (Nittler 1997; CHWG). In our study, the three low ${ }^{18} \mathrm{O} /{ }^{16} \mathrm{O}$ grains (S-C6071, S-C6106 and S-H6205), which fall at the end of CBP trend (Fig. 2), also have very high $\left({ }^{26} \mathrm{Al}{ }^{27} \mathrm{Al}\right)_{0}$ of $1-3 \times 10^{-2}$. At the temperatures at which $\mathrm{CBP}$ occurs, the rate of production of ${ }^{26} \mathrm{Al}$ via ${ }^{25} \mathrm{Mg}(p, \gamma)^{26} \mathrm{Al}$ may be high enough to contribute significant ${ }^{26} \mathrm{Al}$ to the envelope (Nittler 1997; Busso et al. 1999). The low level of ${ }^{41} \mathrm{Ca}$ in S-H6205 implies little contribution from the He shell to the envelope. These observations would suggest that S-H6205 grain formed in the winds of a $\sim 1.2 M_{\odot}$ star during the late red giant stage or early AGB stage.

\section{SUMMARY AND CONCLUSIONS}

Two hibonite and 12 corundum grains were identified as circumstellar condensates based on highly anomalous isotopic compositions. The discovery of hibonite means that all three major refractory oxides expected to condense from cooling stellar ejecta with $\mathrm{C} / \mathrm{O}<1$ and to survive the chemical processing (corundum, hibonite, and spinel) have now been identified among the circumstellar condensates. Eleven of the corundum grains and two hibonite grains have isotopic compositions compatible with formation in red giant and AGB stars (Fig. 2). One hibonite has an $\mathrm{O}$ composition consistent with a $\sim 1.7 M_{\odot}$ AGB star with near solar metallicity. The $\left({ }^{26} \mathrm{Al} /{ }^{27} \mathrm{Al}\right)_{0}=4.7 \times 10^{-3}$ and $\left({ }^{41} \mathrm{Ca} /{ }^{40} \mathrm{Ca}\right)_{0}=1.5 \times 10^{-4}$ of this grain are essentially those predicted by stellar models. In contrast, the second hibonite has an $\mathrm{O}$ composition indicative of CBP, $\left({ }^{26} \mathrm{Al} /{ }^{27} \mathrm{Al}\right)_{0}=2 \times 10^{-2}$, and $\left({ }^{41} \mathrm{Ca} /{ }^{40} \mathrm{Ca}\right)_{0} \leq 3.2 \times$ $10^{-5}$. The low ${ }^{18} \mathrm{O} /{ }^{16} \mathrm{O}$ and high $\left({ }^{26} \mathrm{Al} /{ }^{27} \mathrm{Al}\right)_{0}$ of the grain may both reflect $\mathrm{CBP}$. The low $\left({ }^{41} \mathrm{Ca} /{ }^{40} \mathrm{Ca}\right)_{0}$ may suggest that $\mathrm{S}$ H6205 formed before the third dredge-up engulfed significant amount of $\mathrm{He}$ shell materials. Corundum S-C6087 has a very high ${ }^{17} \mathrm{O} /{ }^{16} \mathrm{O}(0.0075)$ and near-solar ${ }^{18} \mathrm{O} /{ }^{16} \mathrm{O}$. This grain is inconsistent with current stellar models for stars with initial compositions near the Galactic evolution trend.

We thank R. Gallino for valuable comments and suggestions. This work was supported by NASA, NAG5-4083, and NAG58158. Contribution 8644(1035), Division of Geological and Planetary Sciences of Caltech.

\section{REFERENCES}

Anders, E., \& Zinner, E. K. 1993, Meteoritics, 28, 490

Boothroyd, A. I., \& Sackmann, I.-J. 1999, ApJ, 510, 232

Boothroyd, A. I., Sackmann, I.-J., \& Wasserburg, G. J. 1994, ApJ, 430, L77 . 1995, ApJ, 442, L21

Busso, M., Gallino, R., \& Wasserburg, G. J. 1999, ARA\&A, in press

Cameron, A. G. W. 1993, in Protostars and Planets III, ed. E. H. Levy \&

J. L. Lunine (Tucson: Univ. Arizona Press), 47

Choi, B.-G., Huss, G. R., Wasserburg, G. J., \& Gallino, R. 1998, Science, 282, 1284 (CHWG)

Dearborn, D. S. P. 1992, Phys. Rep., 210, 367

Forestini, M., Paulus, G., \& Arnould, M. 1991, A\&A, 252, 597

Gallino, R., Busso, M., Picchio, G., \& Raiteri, C. M. 1990, Nature, 348, 298

Gallino, R., Raiteri, C. M., Busso, M., \& Matteucci, F. 1994, ApJ, 430, 858

Heinrich, M., Huss, G. R., \& Wasserburg, G. J. 1998, Lunar Planet. Sci., 29, 1715

Huss, G. R., Fahey, A. J., Gallino, R., \& Wasserburg, G. J. 1994, ApJ, 430, L81

Huss, G. R., Hutcheon, I. D., \& Wasserburg, G. J. 1997, Geochim. Cosmochim. Acta, 61, 5117

Huss, G. R., \& Lewis, R. S. 1995, Geochim. Cosmochim. Acta, 59, 115
Hutcheon, I. D., Armstrong, J. T., \& Wasserburg, G. J. 1984, Meteoritics, 19, 243

Hutcheon, I. D., Huss, G. R., Fahey, A. J., \& Wasserburg, G. J. 1994, ApJ, 425, L97

Nittler, L. R. 1997, in Astrophysical Implications of the Laboratory Study of Presolar Materials, ed. T. J. Bernatowicz \& E. K. Zinner (New York: AIP), 59

Nittler, L. R., \& Alexander, C. M. O. D. 1999, Lunar Planet. Sci., 30, 2041

Nittler, L. R., Alexander, C. M. O. D., Gao, X., Walker, R. M., \& Zinner, E. K. 1994, Nature, 370, 443 1997, ApJ, 483, 475

Nittler, L. R., Alexander, C. M. O. D., Wang, J., \& Gao, X. 1998, Nature, 393,222

Wasserburg, G. J., Boothroyd, A. I., \& Sackmann, I.-J. 1995, ApJ, 447, L37

Wasserburg, G. J., Busso, M., Gallino, R., \& Raiteri, C. M. 1994, ApJ, 424, 412

Wood, J. A., \& Hashimoto, A. 1993, Geochim. Cosmochim. Acta, 57, 2377

Yoneda, S., \& Grossman, L. 1995, Geochim. Cosmochim. Acta, 59, 3413

Zinner, E. K. 1997, in Astrophysical Implications of the Laboratory Study of Presolar Materials, ed. T. J. Bernatowicz \& E. K. Zinner (New York: AIP), 3 